\title{
Human Papillomavirus: A Gender-Based Report on the Knowledge of College Students in Northern Greece
}

\author{
Kavvadas D $^{1 *}$, Kavvada A $^{1}$, Ziampa $K^{1}$, Kyriazidi MA ${ }^{1}$, Rousis D $^{2}$ and Chatzidimitriou M $^{2}$ \\ ${ }^{1}$ School of Medicine, Faculty of Health Sciences of Aristotle University of Thessaloniki, Thessaloniki, Greece \\ ${ }^{2}$ International Hellenic University, Biomedical Science, Thessaloniki, Greece
}

${ }^{*}$ Corresponding author: Dimitrios Kavvadas, Moudanion 38, Neapoli Thessaloniki, 56728, Greece, Tel: +306949132263; E-mail: dkavvadas@auth.gr

Received date: May 29, 2020; Accepted date: June 03, 2020; Published date: June 10, 2020

Citation: Kavvadas D, Kavvada A, Ziampa K, Kyriazidi MA, Rousis D, et al. (2020) Human Papillomavirus: A Gender-Based Report on the Knowledge of College Students in Northern Greece. Arch Clin Microbiol Vol. 11 No. 3:110

Copyright: (C) 2020 Kavvadas D, et al. This is an open-access article distributed under the terms of the Creative Commons Attribution License, which permits unrestricted use, distribution, and reproduction in any medium, provided the original author and source are credited.

\section{Abstract}

Title: This study was performed to evaluate the level of basic knowledge of students in Northern Greece regarding human papillomavirus matters, considering each gender's aspect.

Background: In every society it is fundamental that young adults should receive proper education for all Sexual Transmitted Diseases. This study aims on highlighting the necessity of aggressive campaigns, for informing students on HPV. Via a short survey, we performed a key evaluation of the knowledge of students to conclude on whether campaigns for informing students on HPV should be organized by the state.

Methods and Findings: A questionnaire type of survey was undertaken to evaluate the level of basic knowledge of the sample regarding HPV. The questionnaire comprised of 11 questions. The first two questions were to determine specific characteristics of the sample; the third was about the participant's belief of being well educated on HPV, while the rest of them were to evaluate their actual knowledge of the activity, pathogenesis and the national vaccination program against HPV. Five hundred sixty-one students of Northern Greece participated in the study (398 females and 161 males). Regarding their knowledge on HPV, most of the participants declared to be well informed with a rate of $76.1 \%$. Indicatively, it appeared to be an independence regarding gender $(p=0.44)$ about whether HPV can cause cancer to both sexes. As to vaccination, $50.7 \%$ of the participants, regardless gender, believed that HPV vaccine is effective on men ( $p=0.34)$.

Conclusion: Students in Northern Greece seemed to be insufficiently informed about the general activity of HPV, pathogenicity, and vaccine's effectiveness ( $p=0.00001)$. Similar surveys should be launched in the whole country for a proper evaluation to be obtained. The outcome of these studies could be rather beneficial in organizing educational campaigns for students of Greece and, if it is needed, to other countries as well.

Keywords: HPV; Gender; Greece; Knowledge; Epidemiology; Vaccination; Cervical cancer

\section{Introduction}

Human papillomavirus (HPV) family is composed of many strains with mutual characteristics, such as the lack of envelope and the small diameter (up to $55 \mathrm{~nm}$ ) [1]. Moreover, all HPVs include a double stranded circular DNA molecule and intraepithelial pathogenic agents. Contamination depends solely on the completion of the keratinocyte's differentiation cycle. The expression of viral genome is limited in keratinocytes, since there has been no evidence that viral genes are expressed to any other cell's types [2]. The nonstructural proteins E1 to E8 and the L1 protein participate not only to the installation of the virus in host cells, but also in the infectivity of the various strains $[3,4]$.

The Center for Disease Control and Prevention (CDC) underlines that $90 \%$ of HPV infections are going to be eradicated in the next two years. However, given environmental factors, there is always a possibility of benign or malignant neoplasm appearance [4,5]. HPV 16 and 18 strains are high-risk types, as they are responsible to $75 \%$ of cervical cancer's appearances. They are also held accountable for $50-75 \%$ of vaginal and vulvar cancer cases [6-8]. Across the globe, HPV-related cancerous rates fluctuate to $100 \%$ of cervical, $88 \%$ of anal, and less than $50 \%$ of lower genital tract and oropharyngeal [9].

Regarding female gender, over the past three decades, the cervical cancer remains the second leading cause of cancerous-related deaths in women. Every year, about 500,000 women develop the disease, while approximately 240,000 die [10]. In 1997, an epidemiological study carried out in Greece detected the HPV types 16, 18, and 31 in patients with cervical 
cancer at levels of $56 \%, 23 \%$ and $6 \%$ respectively [11]. During the years 2003-2006, another study was conducted by St. Savvas oncology hospital in Athens, which detected HPV infection in patients with cervical cancer, aged $18-48$ years, at a rate of $47.3 \%$. The most common HPV types on the study sample was the low risk HPV-11 (13.4\%) and the high-risk HPV-18 (10.3\%) [12]

On the other hand, HPV associated cancer is rare for men (approximately $1.6 / 100,000$ in general population). More specifically, HPV can cause rectum, penile and oropharyngeal cancer, with the last one being observed, in several countries, at higher rates on men compared to women [9]. Also, $45 \%$ of men present an indication of HPV infection, over a rate of $40 \%$ for women (age ranges: 18-59). Additionally, a $25 \%$ of males from the above rates are infected by high risk HPV types, while the equivalent of females is estimated at $20 \%$ [13].

Nowadays, HPV vaccine has been proven to be the most effective shield against HPV infections. Specifically, the new 9valent vaccine protects from the high-risk types $16,18,31,33$, $45,52,58$, and the low-risk types 6 and 11 . The vaccination can be applied on both boys and girls from the age of 9 to the age of 45 and 26, for women and men respectively $[14,15]$. From 2017, the vaccination program for HPV is recommended by the National Immunization Programs in 71 countries, while vaccine is administered for free to both girls and boys by 11 of those countries [16]. In April 2019, the European Centre for Disease Prevention and Control (ECDC) reinforced the efforts to include the vaccination on males [17]. Therefore, more and more countries tend to incorporate the masculine gender in their official vaccination program, with United Kingdom to be the most recent example [18]. It must be pointed out that being sexually active does not cancel the effectiveness of vaccine. On the contrary, shielding from the remaining types is essential $[14,15]$.

In Greece, the National Immunization Program has been including HPV vaccination since September 2006. Nowadays, the program joins girls aged of 11 to 18 years and special groups between the age of 18 to 26 who are categorized as "special occasions" $[14,19]$. In these specific groups are being included women with chronic diseases, medical and nursing personnel and men who have sex with other men. The vaccine is being administered to feminine gender, excluding male population from the National Program [20].

The above analysis is an evidence that general population, especially students, must possess adequate knowledge on HPV facts. Several countries have attempted to measure the awareness of general population on HPV pathogenesis, vaccination programs and gender aspects. It seems that this kind of evaluation is quite useful when it comes to organizing and launching educational campaigns, especially to young adults [21-28]

The present study was designed as a survey to provide the statistics and vital information regarding HPV awareness among students of northern Greece. The rationale is to focus on each gender's point of view on HPV and the association that presents to both males and females.

\section{Material and Methods}

The questionnaire was distributed to universities and college students of Northern Greece. Medical and hygiene students were excluded from the survey. There was no age limitation. The survey was launched via social media to Northern Greece University forums and academic blogs, of which the aggregate of members was known. As a result, due to the average assemblage of each group's members, the total population of our study rises approximately to 100,000 . In order to extract a randomized sample out of all students of Northern Greece, we made sure that our survey was launched to many different institutional forums and blogs (e.g. Aristotle University of Thessaloniki, University of Macedonia, International Hellenic University of Thessaloniki etc.). The amount of the responders building up our randomized sample is 561. The needed sample size was calculated, with a confidence level of $99 \%$ and a $5.43 \%$ margin of error, at 561 participants that could safely represent a population of 100,000 which is rather representative for Northern Greece student population.

The survey was launched on September 2019 and remained available for responding until 31 December 2019. A primary study was conducted with 96 participants, in which the internal consistency of our questionnaire was checked by using the $\alpha$-Cronbach Test $(\alpha$-factor $=0.8)$. Responders were able to open the survey through a link provided by the authors. All the questions were mandatory. The responders were informed that they were participating in the survey voluntarily and anonymously and that their response was deposited for research purposes only. Prior the main questions the responders were asked to sign that they consent for using and depositing their responses for future research. Additionally, respondents were asked to confirm that they were students (Under-graduate, Post-graduate or PhD), that they were not studying in any school of health sciences and finally, that they had not already submitted an answer to this survey. Every time a respondent fulfilled the survey, date and time signatures were added.

The questionnaire consisted of 11 questions (Table 1). The first question evaluated the rates of male and female participants. The second, estimated the average age rates of the responders. The third was of high importance to evaluate whether our participants believe to be informed on HPV. The next 8 questions determined the actual knowledge of the responders about the clinical manifestation, prevalence of HPV, vaccination, and gender's dependence. More specifically, No.5 evaluated their believes regarding gender's aspect. Questions No.4 and No.9 demanded a strict positive or negative answer. The rest of them (No. 6,7,8,10,11) were more 
debatable of the respondents' knowledge, giving them the opportunity to declare their unawareness.

Table 1 Questions 1 to 11 of the questionnaire are used to evaluate the level of the basic knowledge of the participants regarding HPV; these questions are to determine their biological gender (No. 1), age (No. 2), whether or not the participants believe to be informed (No. 3), and their actual knowledge on HPV (No. 4-11), The bolded counts/rates represent the right responds that evaluate participants' true knowledge on HPV.

\begin{tabular}{|c|c|c|c|}
\hline Question & Answer & $\mathbf{N}$ & $\%$ \\
\hline \multirow[b]{2}{*}{ 1. What is your biological gender? } & Female & 398 & 70.9 \\
\hline & Male & 163 & 29.1 \\
\hline \multirow[b]{3}{*}{ 2. In which category is your age included? } & $<22$ & 169 & 30.2 \\
\hline & $22-30$ & 252 & 44.8 \\
\hline & $>30$ & 140 & 25 \\
\hline \multirow{2}{*}{$\begin{array}{l}\text { 3. Do you believe that you are well informed about } \\
\text { Human Papillomavirus (HPV)? }\end{array}$} & Yes & 427 & 76.1 \\
\hline & No & 134 & 23.9 \\
\hline \multirow{2}{*}{$\begin{array}{l}\text { 4. In your opinion, is Human Papillomavirus responsible } \\
\text { for genital warts? }\end{array}$} & Yes & 417 & 74.3 \\
\hline & No & 144 & 25.7 \\
\hline \multirow{5}{*}{$\begin{array}{l}\text { 5. Regarding gender's aspect, to whom is } \\
\text { epidemiologically HPV more related? }\end{array}$} & Exclusively to women & 23 & 4.1 \\
\hline & Mostly about women & 387 & 68.9 \\
\hline & Mostly about men & 35 & 6.3 \\
\hline & Exclusively to men & 0 & 0 \\
\hline & I am not sure & 116 & 20.7 \\
\hline \multirow{3}{*}{$\begin{array}{l}\text { 6. Could an "HPV Infection" and "Smoking" similarly } \\
\text { result to developing cervical cancer? }\end{array}$} & Yes & 221 & 39.5 \\
\hline & No & 98 & 17.3 \\
\hline & I am not sure & 242 & 43.2 \\
\hline \multirow{3}{*}{$\begin{array}{l}\text { 7. Are there more HPV-related types of cancer than the } \\
\text { cervical one? }\end{array}$} & Yes & 286 & 50.9 \\
\hline & No & 33 & 5.9 \\
\hline & I am not sure & 242 & 43.2 \\
\hline \multirow[b]{3}{*}{ 8. Does HPV cause cancer to both sexes? } & Yes & 277 & 49.5 \\
\hline & No & 86 & 15.3 \\
\hline & I am not sure & 198 & 35.2 \\
\hline \multirow{2}{*}{$\begin{array}{l}\text { 9. In your opinion, is HPV vaccine effective to be } \\
\text { administered to the male gender? }\end{array}$} & Yes & 285 & 50.7 \\
\hline & No & 276 & 49.3 \\
\hline \multirow{3}{*}{$\begin{array}{l}\text { 10. Should the HPV vaccine be administered to sexually } \\
\text { active women? }\end{array}$} & Yes & 393 & 70.2 \\
\hline & No & 71 & 12.7 \\
\hline & I am not sure & 97 & 17.1 \\
\hline \multirow{3}{*}{$\begin{array}{l}\text { 11. Is the vaccination that prevents cervical cancer the } \\
\text { same that shields people from several HPV-valent } \\
\text { types? }\end{array}$} & Yes & 277 & 49.5 \\
\hline & No & 64 & 11.2 \\
\hline & I am not sure & 220 & 39.3 \\
\hline
\end{tabular}

Chi-square test was used on $2 \times 2,3 \times 3$, and $2 \times 3$ contingency tables. Additionally, a good-fitness test was applied on the sample to determine whether the survey was equally fulfilled from both sexes. Every chi-square statistic has been also 
calculated with the popular Yates correction, maximizing the credibility. Finally, a Z-test was conducted to analyze the significance between the number of participants who declare to be informed and their mean scores of right answers (Table 2). Statistical analyses were performed using SPSS (free software for statistical computing-via Auth, http:// www.spss.com), and p-value of significance was regarded as $<0.05$.

Table 2 The participants mean scores of right answers (Questions No. 4 to 11) and their own affirmative answers of being well informed on HPV (Question No. 3), in comparison.

\begin{tabular}{|l|l|l|l|l|}
\hline & N & Mean Score & SE & P-value \\
\hline $\begin{array}{l}\text { 1. Males and } \\
\text { Females }\end{array}$ & 427 & 284.6 & 22.94 & 0.00001 \\
\hline 2. Males & 94 & 62.14 & 5.13 & 0.00001 \\
\hline 3. Females & 333 & 222.43 & 18.3 & 0.00001 \\
\hline
\end{tabular}

$\mathrm{N}$ : number of affirmative answers on Question No.3, SE: standard error, Pvalue: statistical significance to all three studies

\section{Results}

As shown on Table 1, 70.9\% (398) of the participants were women and $29.1 \%$ (163) were men. Additionally, knowing that our target population was equally divided, a good-fitness test was performed regarding the gender and a significant difference was found ( $p=0.0001)$, with female participants to outbalance the males. Regarding participants' age, the majority fluctuated among the ages of $22-30$ (44.8\% of rate). About their knowledge on HPV, most of the participants declared to be informed, with a rate of $76.1 \%$. A percentage of $74 \%$ responded affirmative that HPV was the cause of genital warts, while only $39.5 \%$ declared an affirmative that HPV infection and smoking could both be responsible for developing cervical cancer. Regarding gender's aspect, a rate of $68.9 \%$ believed that, epidemiologically, HPV is related to both genders with women to had more weighted outcomes. On the questions about developing other cancer types than the cervical one, and whether HPV causes cancer to both sexes, a $50.9 \%$ and $49.5 \%$ respectively answered positively. About vaccination, it is reported by $50.7 \%$ of the participants that HPV vaccine was efficient for males, while a $70 \%$ agreed that it should be administered to sexually active women as well. Finally, a $49.5 \%$ believed that HPV vaccine is the same that prevents cervical cancer (Table 1).

As shown on Table 2, the mean score of 427 participants who declared to be informed on HPV and answered right the questions was $284.6(66,7 \%)$. A significant difference was detected to each gender's knowledge analysis as well $(p=0.00001)$.

\section{Discussion and Conclusion}

To begin with, the minority of male participants is rather provocative, pointing out a bias regarding HPV and its' relation to gender. Apart from questions No3 and No10, the present study shows that almost half of the students in northern Greece do not have sufficient knowledge regarding HPV matters. Even a large proportion of those who believe to be informed on HPV is proven to be unaware or misinformed (Table 2). This phenomenon appears to other ethnicities, too. For example, Vongtmann et al. at their study of HPV awareness on Mexican college students, declared that the knowledge on HPV matters is rather limited, although most of them are familiar with the name of the virus [21].

Additionally, it was observed that sufficient information about HPV depends on gender $(p=0.00001)$. More specifically, it was found that women are more aware than men regarding genital warts' cause $(p=0.00005)$. The same fact was concluded for Swedish adults from Dahlström et al. [22].

On the contrary, in regards with the effectiveness of vaccination to masculine gender, there was no significant difference to the answers of each gender $(p=0.34)$, with both sexes to appear poorly informed. Although, studies on United States have pointed out a negativity about males' opinion on HPV immunization [23].

More particularly, trying to compare each gender actual knowledge on the effectiveness of the vaccine on males, we separated the two genders. The comparison that took place was among their response "do you believe you are well informed" and "whether or not the vaccine is effective to be administered to the male gender". It was observed that men were confused on the matter, with the two variables to appear independent $(p=0.06)$. On the contrary, a significant dependence on the same variables appeared to female's sample $(p=0.026)$. Patel et al. has also come to this deduction after a review analysis on European adolescents about HPV and HPV vaccine knowledge [24].

Consequently, even though both sexes appeared to have insufficient knowledge on HPV vaccination, women appeared to be lesser uninformed, as was expected. This might be a result of women's annual pap-test and discussion with their gynecologists, as it has been reported on a study conducted by McBride et al. [25]. The outcome is similar to the comparison of gender and whether or not HPV can cause cancer to both sexes; it appeared to be an independence regarding gender $(p=0.44)$ with the majority of men answering wrong and approximately $50 \%$ of women giving the right answer. When it comes to whether the vaccine prevents only the cervical cancer, a significant gender dependence appeared, with more men declaring unaware or answering wrong in comparison to women $(p=0.001)$. This finding showed that approximately $50 \%$ of the whole sample was unaware about vaccine's efficiency against other types of cancer. It is not unprecedented the fact that the immunization against HPV has been underestimated by male gender. Peters et al., on a proportional study, concluded that American males were less likely to be aware of the vaccine. However, the same study has also pointed out an insignificant gender differentiation of the awareness on HPV-associated cancers [26].

Furthermore, it was found that $82 \%$ of participants above the age of 22 believed to be informed about HPV, while only a 
$62 \%$ under the age of 22 declared the same $(p=0.00001)$. Similar age dependence existed between the age and whether the vaccine prevents only the cervical cancer $(p=0.0004)$. About the effectiveness of the vaccine to the masculine gender the variables appeared to be independent $(p=0.16)$, since all responders, despite their age, were confused about whether or not the vaccine should be administered to males (45\%-55\%: Affirmative answers).

Making our final analysis, despite the undeniable fact that many countries have studied the impact of HPV to both genders [4-10] and have put vaccination to males under seriously consideration [18], in Greece, the progress of the studies is limited to merely several cases $[11,12]$. The sample studied in this research indicates the general lack of knowledge and proper education on HPV. This unawareness is endorsed by the attitude of Greece's National Hygiene System which is still excluding male gender from the National Immunization Program, reproducing a gender bias to the matter. As many scientists have pointed out in their studies $[25,27,28]$, it would be rather beneficial that educational campaigns for students of Greece (and especially male students) were to be organized in order to extinguish these biased ideas that have accreted through the years.

\section{Conflict of Interest Statement}

The authors declare no conflict of interest.

\section{References}

1. Hausen Z (2002) H. Papillomaviruses and cancer: From basic studies to clinical application. Nat Rev Cancer 2: 342-350.

2. Gadducci A, Guerrieri M, Greco C (2013) Tissue biomarkers as prognostic variables of cervical cancer. Oncology/Hematology 86: 104-129.

3. Ramqvist T, Grün N, Dalianis T (2015) Human papillomavirus and tonsillar and base of tongue cancer. Viruses 7: 1332-1343.

4. Steben M, Duarte-Franco E (2007) Human papillomavirus infection: epidemiology and pathophysiology. Gynecol Oncol 107: 2-5.

5. Boda D, Docea AO, Calina D, Ilie MA, Caruntu C, et al. (2018) Human papilloma virus: Apprehending the link with carcinogens is and unveiling new research avenues. Int J Oncol 52: 637-655.

6. Walboomers JM, Jacobs MV, Manos MM, Bosch FX, Kummer JA, et al. (1999) Human papillomavirus is a necessary cause of invasive cervical cancer worldwide. J Pathol; 189: 12-19.

7. de Sanjose S, Quint WG, Alemany L, Geraets DT, Klaustermeier $J E$, et al. (2010) Human papillomavirus genotype attribution in invasive cervical cancer: a retrospective cross-sectional worldwide study. Lancet Oncol 11: 1048-1056.

8. Bruni L, Albero G, Serrano B, Mena M, Gómez D, et al. (2019) Human Papillomavirus and Related Diseases in the World: Summary Report. ICO/IARC Information Centre on HPV and Cancer (HPV Information Centre) 67-122.

9. Giuliano AR, Nyitray AG, Kreimer AR, Pierce Campbell CM, Goodman MT, et al. (2015) EUROGIN 2014 Roadmap: Differences in HPV infection natural history, transmission, and HPV-related cancer incidence by gender and anatomic site of infection. International journal of cancer Journal international du cancer 136: 2752-2760.

10. JinXW, Lipold L, Sikon A, Rome E (2013) Human papillomavirus vaccine: safe, effective, underused. Cleve Clin J Med 80: 49-60.

11. Labropoulou V, Diakomanolis E, Dailianas S, Kalpaktsoglou K, Balamotis A, et al. (1997) Type-specific prevalence of genital human papillomaviruses in benign, premalignant, and malignant biopsies in patients from Greece. Sex Transm Dis 24: 469-474.

12. Panotopoulou E, Tserkezoglou A, Kouvousi M, Tsiaousi I, Chatzieleftheriou G, et al. (2007) Prevalence of human papillomavirus types $6,11,16,18,31$ and 33 in a cohort of Greek women. Journal of Medical Virology 79: 1898-1905.

13. Health Information and Quality Authority (2018) Draft Health Technology Assessment (HTA) of HPV vaccination of boys. HIQA 3: 24-78.

14. EPAR Gardasil (2016) 9human papillomavirus 9-valent vaccine (recombinant, adsorbed). EPAR summary for the public Last Updated.

15. EPAR Cervarix (2018) product information. EPAR summary for the public. Last Updated.

16. WHO (2017) Weekly Epidemiological Record 92: 393-404.

17. ECDC (2019) Scientific Advice: Public consultation on draft guidance for introduction of HPV vaccines in EU countries: focus on 9-valent HPV vaccine and vaccination of boys and people living with HIV. ECDC 3: 11-14.

18. Department of Health and Social Care (2018) Equality AnalysisHuman Papillomavirus Vaccination. GOV.UK, 27-30.

19. Ministry of Health; Official Bulletin (2017) National Vaccination Program for young kids and adolescents. General office of Public Health and Services; Register.

20. Ministry of Health; Official Bulletin (2018) National Vaccination Program for adults. General office of Public Health and Services; Register Number.

21. Vogtmann E, Harlow SD, Valdez AC, Valdez JCC and Ponce EL (2011) HPV knowledge in Mexican college students: implications for intervention programmes. Health \& Social Care in the Community 19: 148-157.

22. Dahlström LA, Sundström K, Young C (2012) Awareness and Knowledge of Human Papillomavirus in the Swedish Adult Population. Journal of Adolescent Health 50: 204-206.

23. Keelan J, Pavri V, Balakrishnan R, Wilson K (2010) An analysis of the Human Papilloma Virus vaccine debate on MySpace blogs. Vaccine 28: 1535-1540.

24. Patel H, Jeve YB, Sherman SM, Moss E (2016) Knowledge of human papillomavirus and the human papillomavirus vaccine in European adolescents: a systematic review. Sex Transm Infect 92: 474-479.

25. McBride KR, Singh S (2018) Predictors of Adults' Knowledge and Awareness of HPV, HPV-Associated Cancers, and the HPV Vaccine: Implications for Health Education. Health Education \& Behavior 45: 68-76.

26. Osazuwa-Peters N, Boakye E, Mohammed K, Tobo B, Geneus C, et al. (2017) Not just a woman's business! Understanding men and women's knowledge of HPV, the HPV vaccine, and HPVassociated cancers. Preventive Medicine 99: 299-304. 
27. Moss L, Reiter PL, Brewer T (2015) HPV vaccine for teen boys: Dyadic analysis of parents' and sons' beliefs and willingness. Preventive Medicine 78: 65-71.

28. Krawczyk A, Perez S, Lau E, Rosberger Z, Stephenson E (2013) Deconstructing Human Papillomavirus (HPV) Knowledge:
Objective and Perceived Knowledge in Males' Intentions to Receive the HPV Vaccine. American Journal of Health Education 44: 26-31. 